\title{
Semi Circular Flipping Blades Sail Type Wind Turbine
}

\author{
Kulwant Singh Dhanoa', Gurleen Dhanoa ${ }^{2}$, Kanwarpreet Singh Cheema ${ }^{2}$ \\ India $+91-9646768001$ \\ Xenoprbhpp2@bbmb.nic.in
}

\section{Extended Abstract}

The goal is to make a wind turbine that is simple in design, generates (approx. $200 \%$ ) more than with respect to conventional turbines in open area and (approx.700 \%) increase in energy harnessing in Cities where wind is turbulent, as this design has overcome many shortcoming of the present day wind turbines. This way the energy can be harnessed in the cities also, i.e. load centres, saving upon the transmission and distribution charges, free from all the complex factors that need to be taken for the feasibility of the wind turbine. So, in simple words, high returns from the money invested. It will also help save the environment as compared to present wind turbines as it will not increase the temperatures and will be bird friendly too.

This new semi-circular, flipping blades type of wind turbine uses the principle of a sail in the wind turbine, We use the semicircular portion only, by flipping the blades, with the shaft arranged vertically/horizontally through which three stainless steel rods at each end of the shaft are arranged 60 degrees apart.

These three are not co-axially same but separated by a distance slightly more than the diameter of the steel rods, with a flexibility of, to and fro motion through the shaft. Mechanical resistance is lowered using linear bearing and polished stainless-steel rods (hollow or solid as per the requirement). At the extreme ends, equiangular steel rods are further joined with steel rods of the length equal to the separation at the main shaft so that equiangular steel rods are parallel to each other when there is no wind force acting on them, and their movement is congruent.

Sail cloth is fitted in the stainless-steel equiangular steel rods (guide rods), suspended from the joining rod between the two guide rods. The sail cloth does not cover the $7 \%$ length of the moving rods, from the main shaft. It is held in place by a steel wire that is fixed to the shaft where the housing for the rods is based.

The arrangement is made so that on the opposite side (i.e. the side opposite to the side where we are going to harness the useful energy or upwind sails), the Sail is restricted to rise maximum 7 inches (for rod length of 6 feet) above the dissection line of the Main Shaft. The rise above the dissection line is limited to avoid the reverse force on the sail. The flip mechanism is used to limit the rise of sail. The sail starts the flip action, when it reaches the 120 degree from the horizontal position as it strikes the guides at the farther end. Guide is fitted from 120 degree from the horizontal position to 295 degree from the horizontal position.

The guide is so formed that from 120 degree to \pm 187 degree it pushes the sail rods towards the front side (not linearly), closing the Sail on the trailing end and simultaneously opening the Sail on the forward position. The Sail on the forward end is opened to its fullest when it reaches \pm 7 degree below the horizontal position on the front side. From 187 degree to 295 degree guide keeps the sail height limited to maximum 7 inches (for rod length of 6 feet).

Small duct is also provided to guard the upwind sails and keep the wind in direction, also the duct and the guides are joined together to make one assembly which can be moved in any direction to harness the wind energy from various directions.

Moreover, two or more turbines can be arranged one above the other whose shafts will be revolving in the opposite directions imparting torque to a single/multiple generator for increasing the area for generating wind energy.

Furthermore the flipping of the sails is done in different models restricting to different angles i.e. decreasing the angle during which the flipping action can be completed depending on various factors like length of the sail rods to be flipped, revolutions of the wind turbine, the wind velocity etc. small variations in the efficiency were experienced on the change of the angle in which the flipping action is completed. 